\title{
Malignant acanthosis nigricans, florid cutaneous papillomatosis and tripe palms syndrome associated with gastric adenocarcinoma
}

\author{
Marta Stawczyk-Macieja ${ }^{1}$, Aneta Szczerkowska-Dobosz ${ }^{1}$, Roman Nowicki ${ }^{1}$, Hanna Majewska ${ }^{2}$, Michał Dubowik ${ }^{3}$, \\ Małgorzata Sokołowska-Wojdyło ${ }^{1}$
} \author{
Head of Department: Prof. Roman Nowicki MD, PhD \\ 2Department of Pathology, Medical University of Gdansk, Poland \\ Head of Department: Prof. Wojciech Biernat MD, PhD \\ Department of Gastroenterology, Medical University of Gdansk, Poland \\ Head of Department: Prof. Marian Smoczyński MD, PhD
}

'Department of Dermatology, Venereology and Allergology, Medical University of Gdansk, Poland

\begin{abstract}
Malignant acanthosis nigricans is a rare paraneoplastic skin syndrome mostly associated with gastric adenocarcinoma. Florid cutaneous papillomatosis and tripe palms syndrome are considered to be abortive clinical variants of acanthosis nigricans. Clinical manifestations include pruritic, hyperkeratotic and hyperpigmented plaques with a subsequent formation of velvety papillomas in the involved areas. This case report describes an unusual case of the patient diagnosed with a combination of malignant acanthosis nigricans, florid cutaneous papillomatosis and tripe palms syndrome associated with gastric adenocarcinoma.
\end{abstract}

Key words: acanthosis nigricans, tripe palms, paraneoplastic skin syndrome.

\section{Introduction}

Malignant acanthosis nigricans is a rare paraneoplastic syndrome (with the incidence of approximately 2 out of 12000 patients with cancer), mostly associated with gastric adenocarcinoma, however, coexistence with extra-abdominal malignancies has increased recently [1-5] The exact pathogenesis of the disease is still unclear.

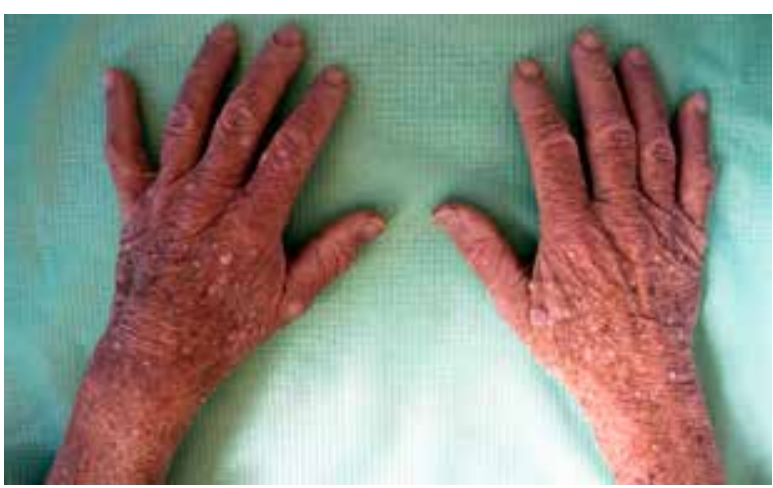

Figure 1. Florid cutaneous papillomatosis: multiple verrucous papules on dorsal sides of hands and forearms
Neoplastic upregulation of transforming growth factor $\alpha$ (TGF- $\alpha$ ) is considered to play a principal role. The combination of malignant acanthosis nigricans, florid cutaneous papillomatosis and tripe palmar syndrome has been even more rare.

We present those three syndromes in the case of one patient associated with gastric adenocarcinoma what, to our best knowledge, was published before only once [6].

\section{Case report}

An 80-year-old man was admitted to the Dermatological Department at the Medical University of Gdansk in April 2012 for the evaluation of generalized wart-like skin lesions of more than 6-month duration. First lesions appeared symmetrically on forearms and dorsal sides of hands (Figure 1) along with hyperpigmentation of skin located mainly in flexural areas, armholes and inguinal folds as well as in the neck and anogenital area. The patient was treated with cryotherapy, with only a mild improvement, followed by a gradual increase in the size

Address for correspondence: Małgorzata Sokołowska-Wojdyło MD, PhD, Department of Dermatology, Venereology and Allergology, Medical University of Gdansk, 7 Dębinki St, 80-211 Gdansk, Poland, e-mail: mwojd@gumed.edu.pl

Received: 25.06.2013, accepted: 18.09.2013. 

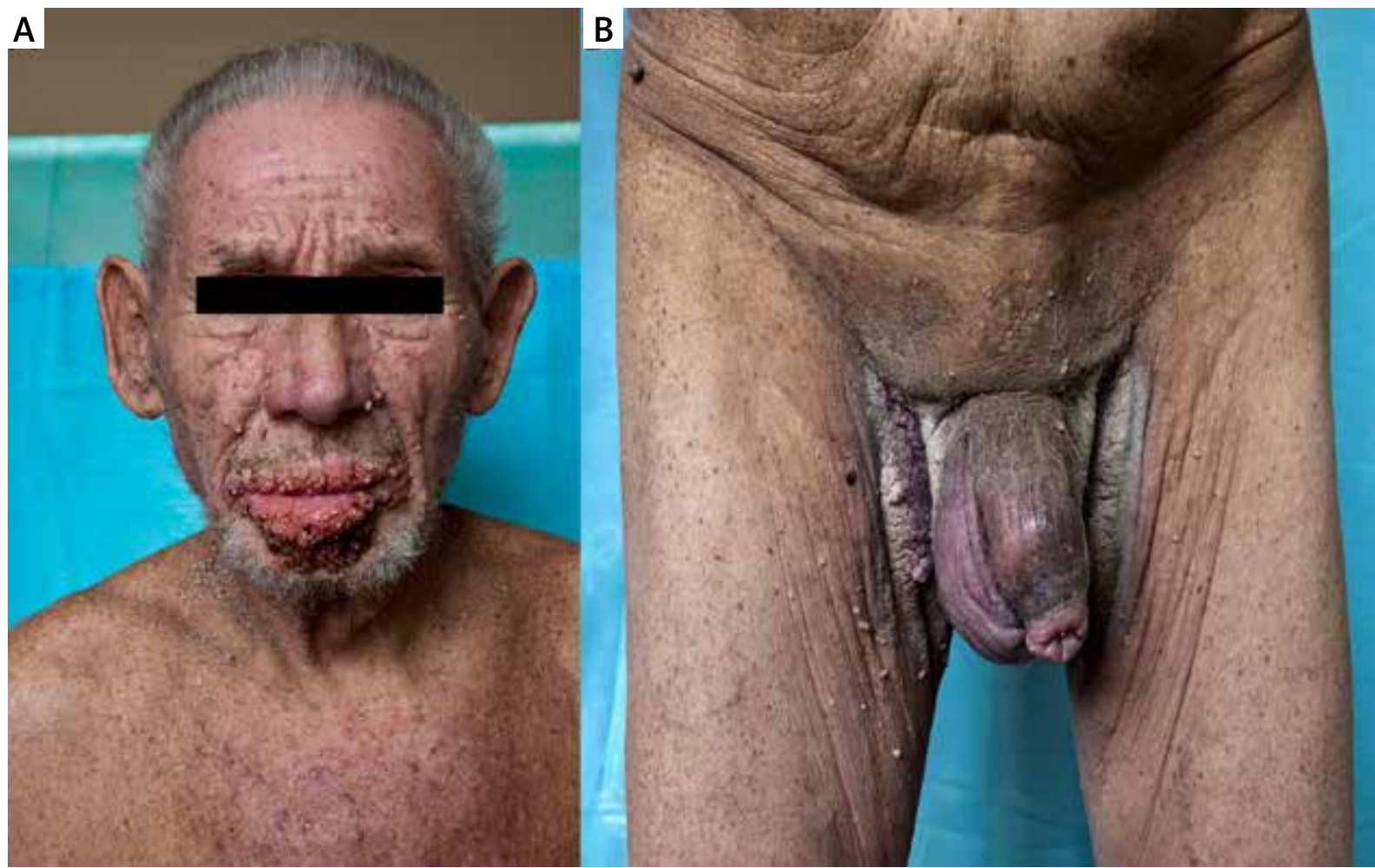

Figure 2. A - Disfigurement of the lips caused by enormous papillomatous lesions and multiple wart-like lesions on the skin of the face and trunk. B - The inguinal folds and scrotum area severely affected by hyperpigmentation typical of acanthosis nigricans with multiple papillomatous lesions

and number of papillomas and involvement of oral, perioral (Figure $2 \mathrm{~A}$ ) and anogenital area (Figure $2 \mathrm{~B}$ ) by multiple verrucous papules. Moreover, a diffuse velvety hyperkeratosis of both palms was observed (Figure 3). Pruritus was slightly pronounced. General examination did not reveal peripheral adenopathy or organomegaly. Weight loss of $30 \mathrm{~kg}$ in the previous 3 years, constipations and altered taste were also reported. The body mass index (BMI) on admission was $21.8 \mathrm{~kg} / \mathrm{m}^{2}$. The patient had a 23-year history of diabetes mellitus, treated with insulin for last 3 years. He also underwent cholecystectomy in 2003.

Laboratory tests (full blood cell count, electrolytes, liver enzymes, C-reactive protein, serum urea, serum creatinine, serological tests for syphilis, HIV, HBsAg, HCV, antinuclear antibodies and urinalysis) did not reveal any pathology, except the elevated serum level of carcinoembryonic antigen (CEA): $142.79 \mathrm{ng} / \mathrm{ml}$. The biopsy specimen taken from the lower lip has revealed the papillary structure with hyperkeratosis and mild acanthosis.

The coincidence of acanthosis nigricans, florid cutaneous papillomatosis and tripe palmar syndrome was diagnosed, what had forced us to search for the underlying malignancy. Chest X-ray as well as abdominal ultrasound imaging were normal. A contrast-enhanced computed tomography (CT) of the abdomen showed a pathological mass in the stomach and intraabdominal adenopathy. The upper gastrointestinal tract endoscopy had revealed esophageal papillomatous polyposis and a submucosal tumor involving gastric cardia and fundus diagnosed as tubular adenocarcinoma in histopathological examination. The patient underwent a total gastrectomy with lymph node dissection and was referred for further oncological treatment.

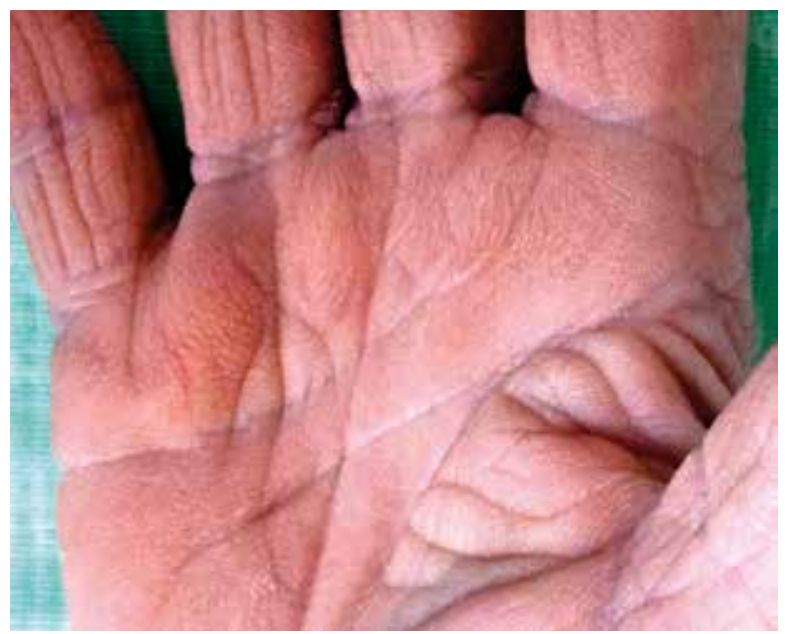

Figure 3. Tripe palms syndrome 


\section{Discussion}

Malignant acanthosis nigricans occurs in the adulthood with a high prevalence after the fifth decade of life. In most cases, cutaneous manifestation precedes the diagnosis of internal neoplasm [7]. In general, it is associated with a high degree of malignancy. Therefore, the prognosis is rather poor. Clinical manifestations of malignant acanthosis nigricans include pruritic, hyperkeratotic and hyperpigmented plaques with subsequent formation of velvety papillomas in the involved areas. Distribution of skin lesions is symmetrical. Flexures, skin folds, neck, nipples and anogenital area are typically affected. In contrast to benign variants of acanthosis nigricans, the paraneoplastic forms are characterized by abrupt onset, rapid progression and more extensive skin and mucosa involvement.

Other paraneoplastic skin syndromes such as Leser-Trelat sign, florid cutaneous papillomatosis and tripe palms syndrome are considered to be abortive clinical variants of acanthosis nigricans [4]. However, these disorders may also evolve independently as isolated forms. Florid cutaneous papillomatosis is characterized by sudden eruption of multiple verrucous skin lesions, located primarily on the dorsal surface of hands and wrists. The clinical manifestation is difficult to distinguish from common warts, however histological features typical of viral warts, like epidermal vacuolization or eosinophilic infiltration are not present [6]. The progression of underlying neoplasia including metastases usually result in more generalized development of skin lesions. The biggest published review consisting of 23 cases of florid cutaneous papillomatosis, revealed that this dermatosis is predominantly associated with gastric adenocarcinoma [8]. The tripe palmar syndrome is a rare form of acquired non-familial palmoplantar keratoderma. This phenomenon is characterized by development of diffuse hyperkeratosis on the palmar side of hands. According to Cohen et al., the association with internal malignancy (most often lung cancer) amounts to 90\%. On the other hand, the coexistence of acanthosis nigricans and tripe palms is associated rather with gastric neoplasia [9].

Histological features of acanthosis nigricans are similar in both malignant and benign forms. Hence, the microscopic examination of a skin biopsy specimen does not allow to differentiate between two variants of the disease [10]. Histopathological findings usually include hyperkeratosis, and papillomatosis with mild hyperpigmentation at the basal layer [11]. These data remain consistent with our case.

The mainstream therapy should be aimed at the underlying neoplasm. Although the efficacy results are usually unsatisfactory, there have been some reports on improvement of skin lesions after surgical or chemotherapeutical treatment of malignancy [12]. The relapse of cutaneous symptoms may indicate the progression or recurrence of the primary tumor [13]. Dermatological treat- ment of skin lesions in malignant acanthosis nigricans includes orally administered retinoids, cyproheptadine and PUVA therapy (psoralen and UVA therapy). Only a few observations have confirmed the clinical improvement after treatment with topical calcipotriol, topical 5-fluorouracil or systemic retinoids [14, 15]. In our case, orally administered acitretin has led to a mild clinical reduction of papillomatosis localized in the area of mouth before the planned surgery of gastric adenocarcinoma.

It is noteworthy that the presented case is an unusual clinical manifestation of three paraneoplastic syndromes combined together.

\section{References}

1. Rigel DS, Jacobs MI. Malignant acanthosis nigricans: a review. J Dermatol Surg Oncol 1980; 6: 923-7.

2. Lenzner U, Ramsauer J, Petzoldt W, et al. Acanthosis nigricans maligna. Hautarzt 1998; 49: 41-7.

3. Ortega-Loayza AG, Ramos W, Gutierrez EL, et al. Cutaneous manifestations of internal malignancies in a tertiary health care hospital of a developing country. An Bras Dermatol 2010; 85: 736-42.

4. Andreev VC. Malignant acanthosis nigricans. Semin Dermatol 1984; 3: 265-72.

5. Olek-Hrab K, Silny W, ŻabaR, et al. Co-occurrence of acanthosis nigricans and bladder adenocarcinoma - case report. Contemp Onkol (Pozn) 2013; 17: 327-30.

6. Brinca A, Brites MM, Figueiredo A, et al. Florid cutaneous papillomatosis and acanthosis nigricans maligna revealing gastric adenocarcinoma. An Bras Dermatol 2011; 86: 573-7.

7. Schwartz RA. Acanthosis nigricans, florid cutaneous papillomatosis and the sign of Leser-Trelat. Cutis 1981; 28: 319-34.

8. Gheeraert P, Goens J, Schwartz RA, et al. Florid cutaneous papillomatosis, malignant acanthosis nigricans and pulmonary squamous cell carcinoma. Int I Dermatol 1991; 30: 193-7.

9. Cohen PR, Grossman ME, Silvers DN, et al. Tripe palms and cancer. Clin Dermatol 1993; 11: 165-73.

10. Kleikamp S, Boehm M, Frosch P, et al. Acanthosis nigricans, papillomatosis mucosae und "tripe palms" bei einem patientem mit metastasiertem magencarcinom. Dtsch Med Wochenschr 2006; 131: 1209-13.

11. Koyama S, Ikeda K, Sato M, et al. Transforming growth factor-alpha (TGF-alpha) producing gastric carcinoma with acanthosis nigricans: an endocrineeffect of TGF-alpha in the pathogenesis of cutaneus paraneoplastic syndrome and epithelial hyperplasia of the oesophagus. J Gastroenterol 1997; 32: 71-7.

12. Anderson SHC, Hudson-Pfacock M, Muller AF. Malignant acanthosis nigricans: potential role of chemotherapy. $\mathrm{Br}$ J Dermatol 1999; 141: 714-6.

13. Longhsore S, Taylor J, Kennedy A, et al. Malignant acanthosis nigricans and endometrioid adenocarcinoma of the parametrium: the search for malignancy. Am Acad Dermatol 2003; 49: 541-3.

14. Swineford SL, Drucker CR. Palliative treatment of paraneoplastic acanthosis nigricans and oral florid papillomatosis with retinoids. J Drugs Dermatol 2010; 9: 1151-3.

15. Bohm M, Luger TA, Metze D. Acanthosis nigricans associated with transitional cell carcinoma of the bladder - symptomatic treatment with calcipotriol autarzt. 1999; 50: 593-6. 